\title{
Disorder of pyrimidine metabolism
}

INSERM

\section{Source}

INSERM. (1999). Orphanet: an online rare disease and orphan drug data base. Disorder of

pyrimidine metabolism. ORPHA:79193

ANPM 